\title{
Trajetórias, percepções e inquietações de terapeutas ocupacionais do Estado de São Paulo no âmbito das práticas da terapia ocupacional no hospital*
}

\section{Trajectories, perceptions and concerns of occupational therapists in the State of São Paulo in the scope of occupational therapy practices in the hospital}

\author{
Sandra Maria Galheigo ${ }^{1}$, Larissa de Almeida Alves Tessuto ${ }^{2}$
}

GAlHEIGO, S. M.; TESSUTO, L. A. A. Trajetórias, percepções e inquietações de terapeutas ocupacionais do Estado de São Paulo no âmbito das práticas da terapia ocupacional no hospital. Rev. Ter. Ocup. Univ. São Paulo, v. 21, n. 1, p. 23-32, jan./abr. 2010.

RESUMO: Este artigo se propõe a apresentar as trajetórias, percepções e inquietações de terapeutas ocupacionais e docentes de terapia ocupacional em programas hospitalares, representando parte dos resultados de pesquisa cujo objetivo foi o de conhecer as percepções e representações desses profissionais sobre as práticas hospitalares da terapia ocupacional. Foram entrevistados vinte e três terapeutas ocupacionais e/ou docentes de terapia ocupacional de hospitais universitários e hospitais-escola do Estado de São Paulo através de entrevistas semi-estruturadas. Os resultados apontam que, para os entrevistados, o trabalho do terapeuta ocupacional no hospital é promissor, sua atuação contribui para a redução do tempo de internação, de complicações, seqüelas, e reinternações. Referem que o terapeuta ocupacional oferece escuta diferenciada, atendendo de forma ampliada as necessidades dos sujeitos sob cuidado. Com relação às dificuldades, apontam, dentre outros, para o hibridismo das bases teórico-metodológicas usadas; a invisibilidade e a desvalorização do trabalho e a falta de organização da categoria profissional. Apoiando-se nas reflexões de Bourdieu, o artigo conclui que os terapeutas ocupacionais no hospital têm ainda pouco capital simbólico e econômico e que necessitariam compensar sua condição atual, por meio do desenvolvimento do capital cultural, investindo na graduação e na educação permanente, e do capital social, promovendo uma maior organização social entre aqueles que trabalham nas instituições hospitalares.

DESCRITORES: Terapia ocupacional/tendências. Assistência hospitalar. Hospitais universitários/ recursos humanos. Serviço hospitalar de terapia ocupacional.

\footnotetext{
* Artigo produto de projeto de pesquisa Práticas hospitalares em terapia ocupacional: um estudo sobre a consolidação do campo no Estado de São Paulo, que a pesquisadora vem desenvolvendo com o apoio do CNPq.

${ }^{1}$ Professora doutora, docente do Departamento de Fisioterapia, Fonoaudiologia e Terapia Ocupacional da Faculdade de Medicina da USP.

${ }^{2}$ Terapeuta ocupacional, terapeuta ocupacional da equipe de saúde mental da OSS Santa Marcelina.

Endereço para correspondência: Centro de Docência e Pesquisa em Terapia Ocupacional da FMUSP. Rua Cipotânea, 51 - Cidade Universitária, 05508-900, São Paulo-SP.
} 


\section{INTRODUÇÃO}

$\mathrm{A}$ consolidação de um campo de saber e de prática depende necessariamente de sua vitalidade. Esta pode ser dimensionada pela qualidade e amplitude de seu desenvolvimento tecnológico e de sua produção de conhecimento, e pela garantia de que ambos sejam largamente compartilhados com comunidades de estudiosos ou profissionais afins. Se pensarmos no setor saúde, os saberes e práticas produzidos têm também como meta atender às demandas de saúde da população, cumprindo assim seu papel social e, consequentemente, adquirindo legitimidade e reconhecimento social. O dinamismo de um campo é igualmente fomentado pela qualidade da interatividade entre a pesquisa, a educação (graduada, continuada e pós-graduada) e os cenários de prática. Assume destaque nesse processo a efetividade da divulgação de conhecimento seja através da publicação em periódicos, da participação em eventos científicos e, da validação desses novos produtos pelos profissionais do campo, num processo de constante reciclagem e aprimoramento.

Entretanto, é importante assinalar que todo esse processo não acontece num vazio contextual - social, cultural, econômico e político. Ao contrário, a consolidação de um campo que produz saberes e práticas está intrinsecamente associada ao capital que este consegue produzir e acumular. Se tomarmos como perspectiva a proposição de Bourdieu (BONNEWITZ, 2003; BOURDIEU; WACQUANT, 1992; ORTIZ, 2003) acerca dos capitais de um campo, temos: o capital econômico, entendido como a produção e acumulação de bens econômicos; o capital cultural, visto como a acumulação da qualificação intelectual produzida pela família e pela educação; o capital social, resultante das relações sociais de indivíduos, grupos e coletividades; e o capital simbólico, que expressa o reconhecimento e a legitimação. Para Bourdieu, os variados campos (político, artístico, científico, da educação, da mídia, etc) que compõem o espaço social, estão imersos em relações de estratificação, hierarquização e conflito, próprias da realidade social. Assim, entre e dentre os diversos campos há comumente uma distribuição desigual desses capitais.

Utilizando esse arcabouço teórico para o campo da produção da saúde, temos que considerar que dentre os diferentes cenários, instituições, categorias profissionais, grupos e agentes sociais que compõem o campo há dinâmicas de competição e tensão que permeiam a produção e acumulação de capitais (GALHEIGO, 2008). No Brasil, a formulação de políticas universais, como o Sistema Único de Saúde, tem colocado norteadores importantes para a gestão dos coletivos de saúde trazendo foco à atenção das necessidades da população. Portanto, os conflitos existentes são compartilhados e colocados em patamares coletivos de discussão e enfrentamento. Mesmo assim, há diferenças derivadas de interesses econômicos, concepções sanitárias, abordagens epistemológicas, legitimação profissional e, acesso a serviços, para citar algumas, que resultam num cenário dinâmico de constante demanda por composição e negociação. Nesse cenário, diferenças de capital podem resultar na adoção de mecanismos compensatórios pelos grupos que se sentem em desvantagem. Como argumenta Peillon (1998), a falta de algum capital faz com que os envolvidos busquem compensação por meio da acumulação maior de outro capital, por exemplo, quando grupos menos reconhecidos (com pouco capital simbólico) buscam se organizar socialmente (aumentando seu capital social) para compensar sua falta de legitimidade ou de acesso. Este exemplo pode se referir tanto a usuários sem acesso a serviços, como aos profissionais sem acesso a trabalho no sistema ou sem reconhecimento profissional.

Trazendo esse debate para a situação da terapia ocupacional, constatamos que, enquanto núcleo profissional que transita por um conjunto de saberes e práticas no campo da produção do cuidado em saúde, ela está imersa na realidade social acima descrita (GALHEIGO, 2008). Contextualizando historicamente o avanço profissional no Brasil, temos que sua produção e divulgação, científica e tecnológica, foram alavancadas há aproximadamente vinte anos com o ingresso de profissionais em programas de pós-graduação strito-sensu, com a criação dos dois periódicos nacionais e com a sistematização bi-anual dos congressos nacionais da categoria. Entretanto, apesar de evidente o crescimento profissional, algumas discrepâncias nos cenários de prática, no conjunto dos saberes produzidos e no desenvolvimento dos domínios de intervenção se mantiveram. Há ainda maior inserção política, produção científica e tecnológica e, reconhecimento social em algumas áreas da terapia ocupacional do que em outras. Infelizmente, as avaliações da produção do conhecimento da terapia ocupacional brasileira e da incorporação do profissional nas diferentes áreas e equipamentos sociais e de saúde, que poderiam oferecer indicadores importantes para comparação, ainda são escassas.

No que se refere às práticas hospitalares em terapia ocupacional no Brasil, pode-se constatar seu desenvolvimento significativo, embora recente. Em estudo realizado sobre a produção científica na área, constatamos um perfil de produção científica desenvolvido na última década, predominante do sudeste, com destaque para a atenção à saúde da criança e do adolescente (incluindo saúde materno-infantil e neonatos) e, com predominância de produção de resumos em eventos e baixa produção de artigos em periódicos 
(aproximadamente $40 \%$ da produção total) (GALHEIGO 2007; GALHEIGO; ANTUNES 2008). Entendendo que a produção científica reflete de alguma forma os cenários de prática, podemos seguramente afirmar que se trata de uma área da terapia ocupacional que demanda investimentos para sua consolidação.

Com o intuito de conhecer melhor os desafios de consolidação das práticas hospitalares da terapia ocupacional, realizamos pesquisa para estudar a percepção que terapeutas ocupacionais e docentes de terapia ocupacional, envolvidos em programas hospitalares em hospitais universitários e hospitais-escola do Estado de São Paulo, tinham sobre o assunto. Estudar esses atores nos pareceu interessante, pois trabalhando com formação de recursos humanos, eles atuam como multiplicadores. $\mathrm{O}$ foco da pesquisa foi o de conhecer como esses profissionais: (a) compreendiam a constituição das práticas hospitalares em relação às suas dificuldades, desafios e perspectivas, e quais suas sugestões para a consolidação da área; (b) avaliavam a pesquisa e produção do conhecimento da terapia ocupacional na área hospitalar; (c) discorriam sobre a fundamentação teóricometodológica de seu trabalho e as tendências para a consolidação das práticas hospitalares da terapia ocupacional no Brasil; e (d) refletiam sobre o impacto das políticas de saúde, em particular a política transversal HumanizaSus (Política Nacional de Humanização), na consolidação da área e na diversificação das ações desenvolvidas pelos terapeutas ocupacionais nos contextos hospitalares.

Dada a extensão dos resultados, o objetivo deste artigo é o de apresentar a caracterização dos entrevistados e de seu contexto de trabalho; suas trajetórias, motivações e inserção na área; suas percepções sobre as características do trabalho no hospital; e, as reflexões que fazem sobre os potenciais e dificuldades para a consolidação da área enquanto um campo de saberes e práticas da terapia ocupacional.

\section{PERCURSOS METODOLÓGICOS}

A pesquisa foi realizada de fevereiro de 2007 a fevereiro de 2009 e se organizou em duas etapas distintas: a das entrevistas individuais e a do grupo focal. Este artigo se concentrará nos resultados da primeira fase. Nessa foram entrevistados vinte e três terapeutas ocupacionais e/ou docentes de terapia ocupacional, envolvidos com programas hospitalares em hospitais universitários e hospitais-escola do Estado de São Paulo. O objetivo de estudar esse conjunto de profissionais era devido a sua experiência prática e seu papel de formador de recursos humanos em saúde. Portanto, era relevante para a pesquisa que participassem no ensino de graduação, em programas de educação continuada ou em pós-graduação lato sensu em terapia ocupacional.

As entrevistas realizadas foram semi-estruturadas e seguiam um roteiro pré-estabelecido, que foi divulgado para o entrevistado antes da realização da entrevista. Era dividida em duas partes: (a) a contextualização do cenário; (b) o estudo das trajetórias profissionais dos entrevistados e de suas percepções e representações sobre as práticas hospitalares da terapia ocupacional. Na primeira parte, ao se fazer a caracterização do trabalho atual, buscava-se entender a partir de que experiência e contexto o entrevistado falava. O objetivo não foi o de conhecer e comparar serviços hospitalares de terapia ocupacional, mas realizar um estudo do cenário hospitalar do entrevistado (nível de complexidade dos serviços, cobertura assistencial, número de leitos, divisões, clínicas e programas, características do trabalho em equipe e inserção do terapeuta ocupacional). Buscou-se também conhecer se havia Programa de Humanização Hospitalar com grupos de trabalho definidos, o engajamento dos profissionais de saúde e do entrevistado (ou do serviço de terapia ocupacional), e ações desenvolvidas. Em termos da inserção profissional, buscava-se saber em que divisões, clínicas e programas, o entrevistado estava inserido, se oferecia atendimento ambulatorial, no leito ou domicílio, ou em programas de apoio à família e a rede social do internado, bem como sua participação em projetos interdisciplinares desenvolvidos no âmbito da assistência e da formação de recursos humanos em saúde.

A segunda parte se propunha a realizar o estudo, propriamente dito, das trajetórias profissionais e das percepções e representações dos entrevistados sobre as práticas hospitalares da terapia ocupacional enquanto campo profissional de saberes e práticas. Os entrevistados foram inicialmente convidados a discorrer sobre sua trajetória de inserção no campo, isto é, quais as motivações que os levaram a trabalhar nessa área, os percursos de contratação ou filiação profissional e os processos das escolhas pelos programas nos quais participam. A seguir, solicitou-se que refletissem acerca dos fundamentos teórico-metodológicos que norteavam suas práticas, sobre suas principais referências (ou quadros de referência), modelos ou abordagens. A terceira temática de interesse da entrevista era referente às percepções dos entrevistados acerca das características e problemáticas da constituição das práticas hospitalares no hospital contemporâneo. O foco era sobre os dilemas, dificuldades e potenciais de ação identificados para a consolidação das práticas no hospital; as considerações sobre o desenvolvimento do domínio teórico-metodológico, a produção científica e a formação de recursos humanos; e as preferências de denominação do campo. No quarto momento, os entrevistados eram solicitados a discorrer sobre 
sua compreensão da interlocução da terapia ocupacional nas práticas hospitalares com as políticas de saúde, em particular, sobre a relação com o Sistema Único de Saúde, a Política Nacional de Humanização e a Política Nacional de Promoção à Saúde. Por fim, abria-se aos entrevistados a oportunidade de tecerem outras considerações que julgassem importantes.

O entrevistado tinha posse do roteiro e podia falar livremente da forma que julgasse mais pertinente, possibilitando a organização do pensamento de forma narrativa e reflexiva, facilitando a fluidez do diálogo, e acesso às suas percepções e representações sobre o campo. Todas as entrevistas foram gravadas e transcritas. Foi colhido o termo de consentimento livre e esclarecido, sendo os participantes informados sobre a pesquisa, sobre o compromisso de preservação de sua identidade, imagem e dignidade, sobre a possibilidade de recusa, desistência ou exclusão de segmentos da entrevista a qualquer momento da pesquisa. $\mathrm{O}$ projeto foi aprovado pelo Comitê de Ética do Hospital das Clínicas da Faculdade de Medicina da Universidade de São Paulo sob o protocolo número 843/06.

Após a fase de transcrição, foi feita a leitura do material, e realizada codificação linha por linha de modo a se compreender o que era relevante nas temáticas discutidas pelos entrevistados. Cada entrevista individual foi recortada em suas unidades de registro (por ex. fundamentações teórico-metodológicas, inquietações, nomeações do campo, etc.) tais como definidas no roteiro. No processo de classificação de informações das entrevistas, as passagens recortadas foram agrupadas por entrevistado e unidade de registro, consituindo o corpus da pesquisa. $\mathrm{O}$ foco da análise de conteúdo foi a 'palavra com significado' identificada a partir da freqüência e importância da informação em relação a determinados temas/questões/conteúdos, da qualidade da reflexão produzida ou das ênfases e emoções que permeavam o discurso. As entrevistas foram assim estudadas não apenas pelos conteúdos manifestos nas falas, mas pelas características do processo de reflexividade do entrevistado, e pelas entrelinhas, isto é, aquilo que transparece nos silêncios, suspiros, falas entrecortadas. Posteriormente, a análise se deu pelo agregado de conteúdos condensados em cada unidade de registro, e, por fim, foi feita a leitura transversal do corpus chegando-se ao aprofundamento da análise e as sínteses finais.

\section{RESULTADOS}

Os resultados de uma pesquisa de cunho exploratório, que visa conhecer as percepções e representações que determinado grupo de pessoas têm sobre determinada realidade ou experiência, devem ser apresentados e entendidos com cautela. Embora os resultados apresentem percepções e sentidos pessoais e seu diálogo com os significados compartilhados socialmente sobre determinada experiência, cenário ou campo, eles não podem ser generalizados, passando a se constituir como verdades inequívocas sobre determinada realidade. Concordamos com Minayo (1999) que:

"não é o campo que nos traz o dado, na medida em que o dado não é 'dado' é 'construído'. É fruto das relações teoricamente elaboradas e dirigidas ao campo e num processo inconcluso de perguntas suscitadas pelo quadro empírico às referências teóricas do investigador" ( $p$. 235).

Assim, a pesquisa buscou por meio do percurso metodológico acima descrito, isto é, através da interpretação do que foi 'construído' nas entrevistas, alcançar um conhecimento compreensivo do 'sentido' e do 'pensado' de um conjunto de profissionais, quando abordados individualmente ou em grupo. Para se pensar o próprio conjunto de entrevistados enquanto um coletivo representativo da profissão buscou-se fazer uma combinação de aspectos no processo da seleção dos sujeitos de pesquisa, tais como: tempo de experiência, formação profissional, área de atuação, município de atuação, dentre outros. Com isso esperava-se que os resultados viessem refletir os cenários da prática e contribuir para a discussão das potências e dilemas do campo estudado. Entretanto, há que se lembrar que para se compreender as problemáticas da constituição do campo, há de se articular o 'construído' na pesquisa com o que vem sendo construído coletivamente pelo conjunto de profissionais nas produções científicas publicadas em periódicos, livros e anais de congressos e, debatidos nos eventos científicos e profissionais. São os profissionais que podem, nas diversas instâncias, validar ou refutar esses resultados como tanto outros frutos de investigação científica.

Nesse artigo serão apresentados os resultados gerais referentes às percepções dos entrevistados sobre suas dificuldades, desafios e perspectivas para a consolidação das práticas hospitalares da terapia ocupacional bem como suas sugestões. Para entender de que lugar os entrevistados dialogaram com o pesquisador, será inicialmente, apresentada sua caracterização e a de seus contextos de trabalho.

\section{Caracterização dos entrevistados e de seu contexto de trabalho}

Essa caracterização foi construída a partir das informações colhidas nas entrevistas como a partir de outras fontes como o levantamento bibliográfico realizado durante a revisão da literatura, o Currículo Lattes disponibilizado publicamente pelo Conselho Nacional de Desenvolvimen- 
to Científico (CNPq) e informações disponibilizadas nos sítios eletrônicos das instituições. É importante entender a caracterização como um elemento para a contextualização da pesquisa, não servindo, portanto, para generalizações acerca da caracterização dos profissionais que trabalham na área como um todo ou das instituições onde trabalham.

Conforme apresentado na Tabela 1 , no momento da pesquisa a maioria dos terapeutas entrevistados tinha mais do que 10 anos de formado $(\mathrm{n}=16)$, destacando-se assim sua experiência profissional. Em relação à formação profissional havia um equilíbrio entre os que estudaram em escolas públicas e privadas. Com relação à formação pós-profissional, nove entrevistados haviam cursado programas de aprimoramento profissional em terapia ocupacional (em hospital geral e neurologia), ou, em programas multidisciplinares (em gerontologia ou saúde coletiva). Dezenove entrevistados cursaram especialização. A variedade das áreas de conhecimento, tal como descrito na tabela 1 , revela a busca de formação continuada em domínio específico da ação profissional, o que contribui para o entendimento das tendências e trajetórias profissionais futuras, conforme mostraremos adiante. Com relação à pós-graduação stricto sensu, dentre os entrevistados havia nove mestres, um doutor, três mestrandos e quatro doutorandos. As áreas de concentração de seus programas de pós-graduação, descritas na Tabela 1, seguem o padrão brasileiro para terapeutas ocupacionais, mostrando uma formação variada.

Tabela 1 - Caracterização da formação profissional e da produção científica dos entrevistados

\begin{tabular}{|c|c|c|c|c|c|c|}
\hline \multicolumn{7}{|c|}{ Tempo de formação graduada } \\
\hline $\mathrm{N}^{\mathrm{o}}$ de anos: & \multicolumn{2}{|c|}{$>20$ anos } & \multicolumn{2}{|c|}{$>10$ anos $<20$ anos } & $>5$ anos $<10$ anos & $>5$ anos \\
\hline $\mathrm{N}^{\mathrm{o}}$ de entrevistados & \multicolumn{2}{|l|}{10} & \multicolumn{2}{|l|}{06} & 05 & 02 \\
\hline \multicolumn{7}{|c|}{ Formação pós-graduada lato sensu } \\
\hline \multicolumn{3}{|c|}{ Com aprimoramento profissional: 09} & \multicolumn{4}{|c|}{ Com especialização: 19} \\
\hline \multicolumn{3}{|c|}{$\begin{array}{l}\text { Áreas: } \\
\text { Terapia ocupacional: hospital geral, neurologia } \\
\text { Programas multidisciplinares: gerontologia e saúde } \\
\text { coletiva. }\end{array}$} & \multicolumn{4}{|c|}{$\begin{array}{l}\text { Áreas: terapia da mão, reumatologia, planejamento, administração e/ou gestão } \\
\text { de serviços de saúde, gerontologia, saúde coletiva, Método Bobath e Terapia } \\
\text { Ocupacional Dinâmica (oferecida pelo Centro de Estudos de Terapia Ocupacio- } \\
\text { nal/CETO). }\end{array}$} \\
\hline \multicolumn{7}{|c|}{ Formação pós-graduada stricto sensu } \\
\hline \multicolumn{2}{|l|}{ Mestres: 09} & \multicolumn{2}{|l|}{ Mestrandos:03 } & \multicolumn{2}{|c|}{ Doutores: 01} & Doutorandos:04 \\
\hline \multicolumn{7}{|c|}{$\begin{array}{l}\text { Áreas de concentração: } \\
\text { Ciências, Ciências Médicas; Ciências da Saúde; Ciências da Reabilitação; Educação Especial; Gestão de Serviços de Saúde; Medicina; } \\
\text { Medicina Preventiva e Social; Psicologia; e, Saúde Coletiva. }\end{array}$} \\
\hline \multicolumn{7}{|c|}{ Pesquisa e produção científica } \\
\hline \multicolumn{7}{|c|}{ Produção científica constante (artigos, capítulos de livros e resumos em eventos): $2 / 3$ dos entrevistados } \\
\hline
\end{tabular}

A análise da produção científica dos entrevistados identificou que dois terços participavam regularmente em atividades de pesquisa, na produção de artigos e capítulos de livro, e, em eventos científicos. Dos vinte e três entrevistados, quatro eram membros de Grupo de
Pesquisa cadastrado no Diretório dos Grupos de Pesquisa no Brasil /CNPq.

Em relação à atividade profissional, no momento da entrevista seis dos entrevistados eram docentes de cursos de terapia ocupacional, sendo apenas um em universidade 
pública, dezessete eram responsáveis por supervisão de estágio supervisionado ou de aprimoramento. Oito dos entrevistados desenvolviam concomitantemente atividades de docência na graduação e assistência, nem sempre na mesma instituição. Os demais entrevistados exerciam, em maior ou menor grau, atividades de supervisão de estágios dos cursos de graduação, especialização, residência e aprimoramento profissional. Foram entrevistados profissionais de quatro cidades do Estado de São Paulo, que não serão nomeadas para garantir a privacidade dos entrevistados.

Considerando o cenário de trabalho dos entrevistados, é importante destacar que vinte dos entrevistados trabalhavam em hospitais que oferecem atendimento SUS. Doze entrevistados desenvolviam suas atividades em hospitais de clínicas ligados a Instituições de Ensino Superior (IES) públicas, seis em hospitais universitários, um em hospital-escola de IES privada e dois em hospital privado. Em relação ao grau de complexidade do hospital, dois estavam vinculados a hospitais de retaguarda e dois a hospitais de nível secundário. Os demais dezenove desenvolviam suas ações em hospital geral ou de especialidade, podendo atender alta-média complexidade ou apenas alta complexidade.

Os entrevistados desenvolviam suas práticas em domínios de intervenção variados como mostra a Figura 1. Aqueles vinculados a hospitais gerais prestavam assistência a adultos e idosos (envolvendo ações nas áreas de neurologia, reumatologia e traumato-ortopedia, ginecologia, cardiologia e pneumologia, oncologia, geriatria/gerontologia e cuidados paliativos). Os demais eram vinculados a hospital de especialidade ou a enfermaria específica em hospital geral. Dois referiram estar em programas de saúde mental realizando interconsulta em enfermaria quando solicitados. Três desenvolviam programas para pessoas com doenças infecto-contagiosas (em especial HIV/AIDS), sendo que um acumulava funções no serviço de oncologia. Dois encontravam-se em hospitais de retaguarda, dos quais um adotava a filosofia de cuidados paliativos.

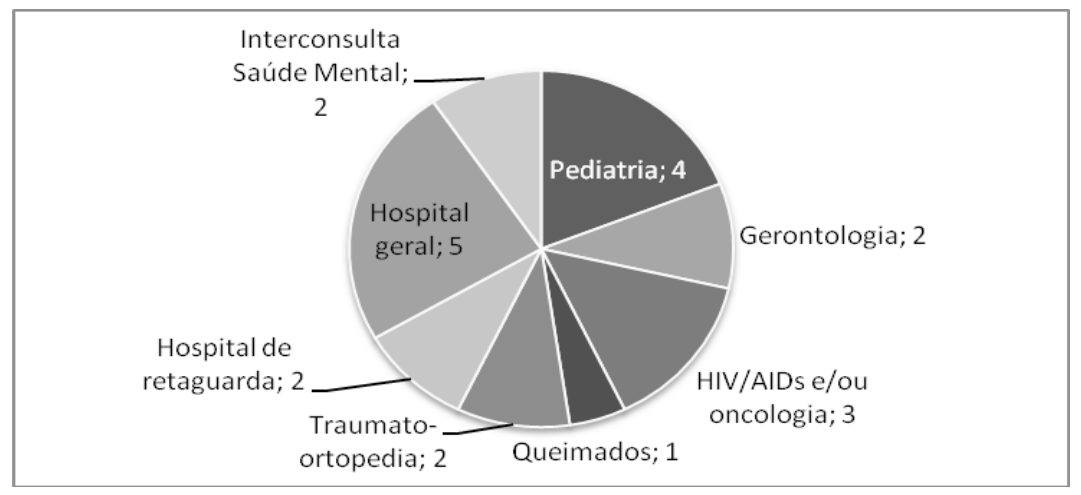

Figura 1 - Domínios de intervenção dos entrevistados

Em geral, os participantes trabalhavam em equipes multiprofissionais, mas referiram que não são todas as unidades do hospital que contam com equipe completa. Dez mencionam reuniões de equipe regulares. Mesmos que não sejam eles próprios os responsáveis pelo programa ou supervisão, dezenove dos entrevistados encontravam-se em hospitais em que se oferece estágio para graduação em terapia ocupacional; doze em locais com oferecimento de programas de aprimoramento profissional em terapia ocupacional e seis de programas de residência multiprofissional ou profissional em terapia ocupacional. Há superposição de mais de uma dessas atividades formativas por entrevistado.

\section{Trajetórias, Motivações e Inserção na Área}

As motivações que levaram os participantes a trabalharem no hospital ou se envolverem com o campo não se distanciam daquelas comumente referidas nas conversas 
profissionais em relação a qualquer área de atuação. Alguns integrantes começaram a se interessar, durante a graduação, pela área hospitalar, ou por uma determinada área ou população (trabalhar em reabilitação física, com crianças ou idosos, por exemplo). A partir dessa motivação inicial, fizeram seu percurso profissional, buscando cursar aprimoramento, especialização e mestrado em assuntos afins. Já outros se aproximaram do campo mais tarde, às vezes durante o aprimoramento e a especialização, quando da oportunidade de prestar um concurso ou lecionar em alguma instituição de ensino superior.

Quatro dos entrevistados fazem referência a ter saído do país para curso de aperfeiçoamento, especialização, estágio ou visita e consideram a experiência importante para sua qualificação profissional e, conseqüente, inserção no campo. Três sinalizaram que se interessaram pelo trabalho no hospital por ele apresentar características ou demandas com as quais se identificam, como por exemplo: gostar de vivenciar desafios; gostar de trabalhos dinâmicos, que exigem flexibilidade e improviso. Como dizem dois entrevistados:

"Cada dia é diferente, o paciente pode continuar internado, pode ter piorado ou ter ido embora havendo outro em seu lugar."

"O hospital é um espaço extremamente importante por ser um espaço de crise, e pode se compreender crise no diagrama chinês como oportunidade, então é a oportunidade de se permanecer ou sair de um estado. $O$ hospital é um lugar onde transitam a vida e a morte; onde transitam diversos saberes tecnológicos; onde convivem perda, morte, separação, dor, sofrimento e mutilação; onde percepções, concepções de saúde e de doença, valores éticos, valores sociais se misturam; isso tudo tem uma complexidade que fazem do hospital por si só, um grande campo do conhecimento e de ação."

A maioria dos entrevistados ingressou no serviço hospitalar por concurso e uns poucos por convite ou indicação. Aqueles com inserção docente ingressaram por concurso na instituição de ensino superior e, foram encarregados pelo ensino prático no campo da assistência hospitalar, e, por conseguinte, pela criação e condução dos programas. A criação de programas e/ou a implantação de serviços aparece de forma constante na experiência dos entrevistados, implicando num duplo desafio - a entrada num novo emprego e o estabelecimento do programa e/ ou serviço. Mostrou-se comum, entre os entrevistados, a implantação de serviços e programas sem prévia experiência com as condições clínicas da população atendida, o que revela uma atitude de vanguarda que o cenário hospitalar ainda demanda do profissional.

Os processos individuais que foram se compondo a partir de interesses pessoais e da construção de percursos profissionais singulares poderiam ser agregados em três trajetórias mais comuns de serem encontradas entre os entrevistados:

a) interesse pela atenção a pessoas sob cuidados clínicos e cirúrgicos, implicando em inserção em hospital com atendimento em leito, áreas de convivência e no domicílio na fase pós-alta, cujo foco da assistência profissional oferecida seja de inspiração holística ou com referência explícita à produção de cuidado humanizado e integral. Tais entrevistados, em geral, realizaram pósgraduação lato ou stricto sensu em gestão de serviços de saúde, saúde coletiva, cuidados paliativos, gerontologia, pediatria, neonatologia, terapia ocupacional hospitalar, e/ ou em algum método terapêutico.

b) interesse por saúde mental, implicando na inserção em serviços de saúde mental em hospital geral ou hospital de especialidade, com atendimento em enfermaria a partir de pedido de interconsulta, cujo foco seja atenção, prioritária, mas não exclusiva da saúde mental do usuário. Tais entrevistados, em geral, realizaram pós-graduação stricto sensu em saúde mental ou lato sensu em Terapia Ocupacional Dinâmica (CETO).

c) interesse pela reabilitação física, implicando na inserção em hospital geral ou hospital de especialidade com atendimento ambulatorial, no leito ou no domicílio cujo foco seja a recuperação da capacidade funcional e a independência nas atividades de vida diária e de vida prática. Tais entrevistados, em geral, realizaram pós-graduação em reabilitação física, terapia de mão, tecnologia assistiva, reumatologia, ou em terapia ocupacional hospitalar e reabilitação física.

Embora essas tendências nas trajetórias dos entrevistados pareçam consistentes e motivo de satisfação pessoal e profissional, é importante salientar que não são estanques, havendo aqueles que transitaram por mais do que uma trajetória. Entretanto, houve também relato de decepções, dificuldades e discordâncias durante a inserção no campo da assistência hospitalar em relação às práticas desenvolvidas em hospitais. Assim, alguns entrevistados relataram que, em algum momento de seu percurso profissional, recusaram ou mudaram de emprego em hospital, pois este trazia conflitos com suas práticas usuais, implicando em mudança de percurso considerada insatisfatória.

Os profissionais demonstram se sentir competentes 
no que fazem, e motivados a continuarem seus trabalhos no hospital. Nenhuma fala de grave descontentamento, cansaço e desapontamento profissional, ou desejo de abandonar o campo foi manifestada durante as entrevistas.

O trabalho no hospital e sua denominação enquanto campo de saber e prática

A discussão acerca da denominação da área ou campo de trabalho do terapeuta ocupacional no hospital não suscitou muito interesse entre os entrevistados, sugerindo ser uma questão menos importante. As manifestações foram no sentido de apoiar mais a denominação Terapia Ocupacional em contextos hospitalares $(\mathrm{n}=7)$. Quatro dos que trabalham com crianças e adolescentes, referiram gostar de uma menção explícita a esse domínio, destacando três nomenclaturas distintas: Terapia Ocupacional em Pediatria $(\mathrm{n}=2)$, Terapia Ocupacional na infância e na adolescência e Terapia Ocupacional sob cuidados clínicos e cirúrgicos na infância e adolescência. Houve uma sugestão por Terapia Ocupacional em cuidados paliativos. As demais manifestações ficaram pulverizadas em torno do termo hospital, das quais destacamos: Terapia Ocupacional em práticas hospitalares; Terapia Ocupacional no hospital geral; Terapia Ocupacional em hospital de reabilitação; Terapia Ocupacional hospitalar; e Terapia Ocupacional nos processos de hospitalização.

\section{Potenciais do campo na perspectiva dos entrevistados}

Houve consonância entre os entrevistados de que trabalho de terapeuta ocupacional no hospital é promissor, com grande potencial de crescimento e desenvolvimento, e com recente melhoria de condições de trabalho. Alguns referiram que a implementação do Sistema Único de Saúde tem sido um facilitador e que tem aumentado o reconhecimento e valorização do trabalho realizado pelo terapeuta ocupacional.

$\mathrm{O}$ crescimento do campo foi também associado à contribuição da terapia ocupacional para a diminuição do tempo de internação, devido ao trabalho preventivo e educativo que realiza. Referiram também que o atendimento precoce oferecido pode trazer resultados mais eficazes com diminuição de complicações, seqüelas, e reinternações. Alguns entrevistados destacaram a importância da compreensão da terapia ocupacional no processo de criação de vínculos com paciente que sofre por estar em um ambiente hostil. Foi referido que a riqueza do campo é determinada pelas demandas que ocorrem e que exigem ações variadas, tais como escuta-acolhimento e técnicas de posicionamento do paciente no leito. Alguns entrevistados destacaram que o terapeuta ocupacional tem uma escuta diferenciada, sensibilidade aguçada e compreensão ampliada das necessidades dos sujeitos sob cuidado, e que sua ação contribui para a construção de um trabalho humanizado. Outros apontaram que o terapeuta ocupacional é um profissional que provoca e incomoda o cotidiano hospitalar cristalizado e que contribui no processo de elaboração diagnóstica. Mencionam que o terapeuta ocupacional tem potencial para trabalhar em equipe, o que o transforma em um intermediário potente na construção e facilitação de comunicação dos agentes das redes de suporte e dos serviços de saúde.

\section{Dificuldades para a consolidação do campo na perspectiva dos entrevistados}

As principais dificuldades referidas pelos entrevistados para a consolidação da terapia ocupacional no hospital foram:

a) o hibridismo das bases teórico-metodológicas usadas;

b) a invisibilidade e a desvalorização de seu trabalho;

c) a falta de organização da categoria profissional;

d) a escassez de recursos humanos e materiais;

e) o insuficiente oferecimento de estágios e de formação continuada.

Assim, no domínio teórico-metodológico, alguns entrevistados referiram que a terapia ocupacional no hospital tem características híbridas atuando com uma mescla de referenciais, permitindo vários modelos, o que causa polarização entre a reabilitação física e a saúde mental. Consideraram, também, que é um campo de grandes dimensões e em constante mudança, mas marginalizado dentro da terapia ocupacional e no próprio hospital.

No domínio prático a relação com os demais profissionais da saúde foi um dos fatores mais referidos como problemáticos para a consolidação do campo, devido à falta conhecimento da profissão pelos demais profissionais da equipe e às relações de poder que se estabelecem no cotidiano da prática. A maioria dos entrevistados referiu não se sentir reconhecido em seu trabalho e ser visto como profissional pouco importante. Alguns relataram que a falta de organização da categoria tem prejudicado ainda mais a inserção do profissional no hospital. Outro fator apontado foi a dificuldade do terapeuta ocupacional se adaptar à rotina hospitalar e se relacionar com o modelo biomédico que permeia as práticas hospitalares. A falta de recursos físicos 
e materiais para o profissional trabalhar no hospital e o baixo retorno financeiro completam as dificuldades descritas pelos profissionais. Com relação ao trabalho propriamente dito, os entrevistados referiram ser uma prática rápida com alta rotatividade e, ao mesmo tempo, um trabalho pesado, isto é, penoso.

No domínio da produção científica, a escassez de publicações foi o fator unanimemente apontado como problemático. Embora, como anteriormente mostrado, dois terços dos entrevistados são ativos produtores de conhecimento da área, há os queixaram que a academia deveria estar produzindo mais conhecimento na área.

No domínio da formação dos recursos humanos, os participantes apontaram que não há formação adequada para o trabalho em hospital geral - formação teórica básica, formação clínica e formação técnica. Alguns afirmaram que a formação ainda está muito focada no modelo médico, dificultando o trabalho no hospital que exige um profissional com perfil para enfrentamento de situações críticas. Há também os que consideraram haver falta de estágios na área hospitalar, o que contribui para a falta de profissionais recém-formados capacitados e dispostos a ingressar no hospital, levando à falta de recursos humanos para atender à demanda.

\section{SÍNTESES E CONSIDERAÇÕES FINAIS}

Este artigo buscou apresentar parte dos resultados sobre pesquisa que estudou a constituição do campo da produção da saúde, em particular, do âmbito da terapia ocupacional nas práticas hospitalares. Acreditamos que pesquisar a perspectiva de profissionais que se encontram em centros formadores nos possibilitaram entender melhor as potencialidades e fragilidades do campo, assim como os enfrentamentos que têm sido feitos para sua consolidação. Os resultados obtidos sem dúvida não podem ser generalizados para o conjunto de terapeutas ocupacionais em hospitais, mas sugerem tendências que devem ser seriamente consideradas.

Primeiramente, os resultados apontam para percepção de que as práticas hospitalares contam com profissionais engajados, que assumam posições de vanguarda, apesar dos percalços que encontram no cotidiano de suas práticas. Entretanto, a pesquisa também nos mostrou que os terapeutas ocupacionais que trabalham em hospitais sentem que são freqüentemente invisíveis, desvalorizados, tem baixos salários e parcos recursos, e, produzem financeiramente pouco, considerando a lógica mercantilista impregnada no setor.
Adotando o argumento de Bourdieu (BONNEWITZ P, 2003; BOURDIEU P, WACQUANT L 1992; GALHEIGO 2008) que um campo (de saber e prática) é um espaço de lutas, um espaço de disputa de poder, onde vários capitais são concorridos, podemos dizer que os profissionais entrevistados mostraram que o terapeuta ocupacional no hospital têm ainda pouco capital simbólico, isto é, é pouco reconhecido e tem pouca legitimação. Podemos também deduzir que os profissionais revelam que têm pouco capital econômico, já que o que produzem não se reverte em cifras de forma imediata e contundente para o funcionamento dos hospitais.

Retomando o argumento de Bourdieu (PEILLON, 1998) que, num determinado campo, o processo de disputa por capitais faz com que seus integrantes busquem compensar com outro capital, quando um mostra-se insuficiente, poderíamos afirmar que os terapeutas ocupacionais que trabalham nos hospitais precisariam compensar com outros dois capitais: o capital cultural (investindo mais na educação e formação) e o capital social (promovendo uma maior organização social entre os pares). Entretanto, os próprios entrevistados revelaram que têm problemas significantes nesses dois capitais também - há pouca organização profissional, dificuldades no domínio teórico metodológico, falta de produção científica, e uma baixa absorção de profissionais no mercado de trabalho.

Acreditamos que acumular capital simbólico é essencial para que determinado grupo profissional, mais do que simplesmente exercer uma luta pela sobrevivência, consiga ser reconhecido e se consolidar. Como já dissemos anteriormente, acreditamos também que quando a divulgação do conhecimento vai além da oralidade das comunicações em eventos científicos e profissionais e, reverte em produções bibliográficas, abre-se uma possibilidade de concretização e disseminação desses conhecimentos de forma mais duradoura.

Portanto, a pesquisa em síntese revela que não existe um hospital imaginário, idealizado e único, no qual o terapeuta ocupacional se insere. Existe de fato um campo de 'protagonismos, interesses e sentido' que requer apropriação, reflexão, organização e enfrentamento. Sem dúvida, há uma nova geração de profissionais se formando para o SUS, assim como docentes e terapeutas que têm acompanhado vários momentos históricos do trabalho no hospital e têm se mantido articulados com as demandas das políticas atuais, buscando reverter as condições desfavoráveis que hoje encontramos.

A pesquisa mostrou que o terapeuta ocupacional acredita na importância de seu trabalho no hospital por possibilitar uma compreensão ampliada da pessoa sob cuidado e uma escuta diferenciada dos sujeitos, diferente dos 
demais profissionais. Assim, ele tem tecnologia suficiente para contribuir para a construção de um trabalho humanizado. Seu trabalho pode prevenir novas internações assim como a diminuição de seu tempo. Contribui para a diminuição de complicações e seqüelas, facilitando a criação de uma rede social de suporte. Sem dúvida, o Terapeuta Ocupacional é um profissional que provoca e incomoda o cotidiano hospitalar evitando sua cristalização e costuma ser um excelente intermediário da rede de saúde, dada sua visão ampliada da condição humana. Esses devem ser os motores para os processos de crescimento e consolidação que ainda são necessários.

Agradecimentos: Gostaríamos de agradecer os entrevistados por sua acolhida e disponibilidade, sem a qual este projeto não poderia ter sido realizado. Agradecemos também Tatiana Amodeo Tuacek e Juliana Russo Antunes pela colaboração durante a coleta de dados e a transcrição das entrevistas.

GALHEIGO, S. M.; TESSUTO, L. A. A. Trajectories, perceptions and concerns of occupational therapists in the State of São Paulo in the scope of occupational therapy practices in the hospital. Rev. Ter. Ocup. Univ. São Paulo, v. 21, n. 1, p. 23-32, jan./abr. 2010.

\begin{abstract}
This paper aims to present the trajectories, perceptions and concerns of occupational therapists and teachers of occupational therapy in hospitalar programs. It represents some of the results of research whose objective was to ascertain the perceptions and representations of these professionals on the hospital practice of occupational therapy. Twenty-three occupational therapists and / or occupational therapy faculty in university hospitals of the State of Sao Paulo were interviewed through semi-structured questions. The results show that, for those interviewed, the work of occupational therapists in the hospital is promising; their performance contributes to the reduction in hospital stay, complications, sequelae, and readmissions. The interviewees state that the occupational therapist provides differentiated listening, taking in a wider sense the needs of individuals under care. Regarding the difficulties, they point out the hybridity of the theoretical and methodological approaches used, the invisibility and devaluation of work and lack of organization of the profession. Drawing on Bourdieu's reflections, the paper concludes that occupational therapists in the hospital still have little symbolic and economic capitals and, to compensate for the current condition, they need to go through the development of cultural capital, investing in continuing education, and of social capital, by promoting greater social organization among those who work in hospitals.
\end{abstract}

KEY WORDS: Occupational therapy/trends. Hospital care. Hospital services. Hospitals, university/ manpower. Occupational therapy department, hospital.

\title{
REFERÊNCIAS
}

BONNEWITZ, P. Primeiras lições sobre a sociologia de Pierre Bourdieu. Rio de Janeiro: Vozes, 2003.

BOURDIEU, P.; WACQUANT, L. An invitation to reflexive sociology. Chicago: The University of Chicago Press, 1992.

GALHEIGO, S. M. Domínios e temáticas no campo das práticas hospitalares em terapia ocupacional: uma revisão da literatura brasileira de 1990 a 2006. Rev. Ter. Ocup. Univ. São Paulo, v. 18, n. 3, p.113-121, 2007.

GALHEIGO, S. M. Terapia ocupacional, a produção do cuidado em saúde e o lugar do hospital: reflexões sobre a constituição de um campo de saber e prática. Rev. Ter. Ocup. Univ. São Paulo, v. 19, n. 1, p.20-28, 2008.
GALHEIGO, S. M.; ANTUNES, J. R. A caracterização da produção bibliográfica nas práticas hospitalares em terapia ocupacional no Brasil: uma revisão da literatura de 1990 a 2007. Rev. Ter. Ocup. Univ. São Paulo, v. 19, p. 91-99, 2008.

MINAYO, M. C. O desafio do conhecimento: pesquisa qualitativa em saúde. $6^{\text {a }}$ ed. São Paulo: Hucitec-ABRASCO, 1999.

ORTIZ, R. A sociologia de Pierre Bourdieu. São Paulo: Olho D'água, 2003.

PEILLON, M. Bourdieu's field and the sociology of welfare. Journal of Social Policy, v. 27, p. 213-229, 1998. 